\title{
High level of hemoglobin, white blood cells and obesity among Sudanese women in early pregnancy: a cross-sectional study
}

\begin{abstract}
Aim: To investigate the association between obesity and anemia/hemoglobin levels. Material \& methods: A cross-sectional study was conducted at Khartoum, Sudan. Obstetric data were collected from 388 pregnant women at mean (standard deviation) of 10.5 (3.1) weeks of gestation using questionnaires. Weight and height were determined, and BMI was calculated. Results: There were 15 (4.4\%), 95 (28.1\%), 127 (37.6) and $101(29.9 \%)$ women who were underweight, normal weight, $\left(18.5-24.9 \mathrm{~kg} / \mathrm{m}^{2}\right)$, overweight $\left(25-29.9 \mathrm{~kg} / \mathrm{m}^{2}\right)$ and obese $\left(\geq 30 \mathrm{~kg} / \mathrm{m}^{2}\right)$, respectively. Hemoglobin levels and white blood cell counts were significantly higher in obese than nonobese groups. Compared with normal BMI, overweight and obesity were associated with higher hemoglobin level. Conclusion: Obese women had higher white blood cell count and hemoglobin level.
\end{abstract}

Lay abstract: Obesity during pregnancy has many maternal and perinatal adverse effects. The current study was conducted to investigate the association between obesity, hemoglobin level and white blood cell count among pregnant Sudanese women in their early pregnancy. Around a third of the 388 women were obese. Hemoglobin level and white blood cells count were significantly higher in obese than nonobese women. Further studies are needed to fully understand the implications of this relationship.

First draft submitted: 31 December 2016; Accepted for publication: 2 February 2017; Published online: 4 April 2017

Keywords: hemoglobin $\bullet$ obesity $\bullet$ pregnancy $\bullet$ Sudan $\bullet$ white blood cells

\section{Background}

The epidemic of obesity is a significant public health problem worldwide, the complications and co-morbidities of which can result in chronic diseases among adults and children [1]. Pregnant women are not protected against this trend among the general population: obstetricians and midwives report seeing an increasing number of obese pregnant women, with prevalence rates around 20\% detected [2]. The situation among African pregnant women, where pregnancy obesity rates have reached very high levels (approaching 50\%), is far more complicated [3,4]. An association between obesity and hemoglobin levels has long been assumed [5,6]. Driven by the current obesity epidemic worldwide, numerous studies have been conducted into the link between obesity and anemia (and/or changes in hemoglobin levels) among the general population [7-9]. Despite this, little research has been done into the same issue during pregnancy. Classical obesityassociated anemia is characterized by dietary iron deficiency, a higher need for iron because of increased blood volume, physical inactivity and low-grade inflammation [7-9]. As part of the bodies' physiological adaptation and preparation for pregnancy, the total blood volume experiences an increase of about $1.5 \mathrm{l}$, in order to meet the demands of the new vascular bed and to anticipate the blood loss occurring at
Abdelmageed Elmugabil', Duria A Rayis², Renda E Abdelmageed ${ }^{2}$, Ishag Adam $^{*, 2}$ \& Gasim I Gasim ${ }^{3}$ ${ }^{1}$ Faculty of Medicine, El Imam El Mahdi University, Kosti, Sudan

2Faculty of Medicine, University of Khartoum, P.O. Box 102, 11111, Khartoum, Sudan ${ }^{3}$ Faculty of Medicine, Alneelain University, Khartoum, Sudan *Author for correspondence: Tel.: +249912168988 Fax: +249183771211 ishagadam@hotmail.com

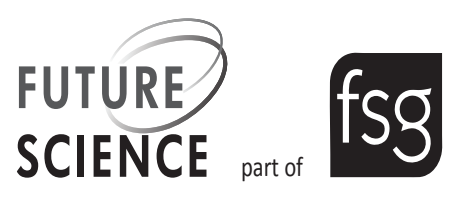


delivery [10]. Along with this, the red cell mass (stimulated by the step up of the maternal erythropoietin production) also increases, however, to a relatively less extent, when compared with the increase in plasma volume, with an overall result being a drop in hemoglobin concentration, resulting in dilutional anemia.

Anemia during pregnancy has been defined by the WHO as a hemoglobin of $<11 \mathrm{~g} / \mathrm{dl}$ [11]. It typically presents with weakness, fatigue, dyspnea and exercise intolerance, a presentation that can significantly preclude weight loss in obese subjects. Likewise, anemia is known to increase the risk of heart failure and mortality [8,12]. Recently, hepcidin (an iron-regulatory protein) has been the target of research, as it is thought to play a key role - along with obesity-associated low-grade inflammation - in the regulation of iron homeostasis [13-16]. However, as there is still a lack of consensus about the association between obesity and anemia [17-20], it is unclear whether obesity itself is a risk factor for developing anemia.

\begin{tabular}{|c|c|}
\hline Variable & $\mathrm{n}=338$ \\
\hline \multicolumn{2}{|l|}{ The mean (SD) of } \\
\hline Age (years) & $27.8(5.5)$ \\
\hline Gravidity & $2.3(1.60$ \\
\hline Parity & $0.9(1.2)$ \\
\hline Gestational age (weeks) & $10.5(3.1)$ \\
\hline Interpregnancy interval (months; $\mathrm{n}=160$ ) & $38.6(2.4)$ \\
\hline BMI, $18.5 \mathrm{~kg} / \mathrm{m}^{2}$ & $27.7(5.7)$ \\
\hline Hemoglobin (gm/dl) & $10.8(1.1)$ \\
\hline White blood cell (cells $\times 10^{9} / \mathrm{l}$ ): & $7740(2174)$ \\
\hline - Neutrophils & $5056(1,820)$ \\
\hline - Lymphocytes & $2167(580)$ \\
\hline Lymphocytes/neutrophils & $0.48(0.41)$ \\
\hline Red cells distribution width (\%) & $13.8(1.5)$ \\
\hline \multicolumn{2}{|l|}{ Number (\%) of } \\
\hline Rural residence & $48(14.2)$ \\
\hline Education level $\leq$ secondary level & $46(13.6)$ \\
\hline Housewives & $252(74.6)$ \\
\hline Anemia & $168(49.7)$ \\
\hline \multicolumn{2}{|l|}{ History of: } \\
\hline - Miscarriage & $73(21.6)$ \\
\hline - Stillbirth & $6(1.8)$ \\
\hline - Gestational diabetes & $5(1.5)$ \\
\hline - Pre-eclampsia & $6(1.8)$ \\
\hline SD: Standard deviation. & \\
\hline
\end{tabular}

Obesity in pregnancy is associated with unfavorable pregnancy outcomes [21], along with increased risk of delivery via cesarean section and higher neonatal intensive care admissions $[22,23]$. These challenging repercussions, and their associated health costs [24], mandate further research into this global problem. Here we investigated the assumed link between obesity and anemia/hemoglobin levels among a population of Sudanese women during early pregnancy.

\section{Materials \& methods Methods}

A cross-sectional study was conducted at Saad Abualila Hospital (Khartoum, Sudan) during the period of January-April 2014. This is a tertiary semiprivate hospital governed by the Faculty of Medicine, University of Khartoum. After giving informed consent, eligible women were enrolled in the study. Inclusion criteria were: early pregnancy ( $<14$ weeks of gestation), singleton pregnancy and willingness to participate in the study. Iron supplement was not yet started and was not recommended in the first trimester. Women with diabetes mellitus, hypertension or any other chronic disease were excluded from the study. A trained medical officer used a questionnaire to gather data from each pregnant women on her age, parity, educational level (illiterate, primary school education or secondary school and above education), occupation (housewife or working mother), gestational age calculated in weeks (based on last menstrual cycle and confirmed by ultrasound) and medical diseases (diabetes, hypertension). Weight and height were determined, and BMI was calculated and expressed as weight in kilograms divided by the square of height in meters. The complete maternal hemogram with blood cell count was measured for all women, using an automated hematology analyzer, as previously described [25-27].

BMI was categorized into four groups: underweight $\left(<18.5 \mathrm{~kg} / \mathrm{m}^{2}\right)$, normal weight $\left(18.5-24.9 \mathrm{~kg} / \mathrm{m}^{2}\right)$, overweight $\left(25-29.9 \mathrm{~kg} / \mathrm{m}^{2}\right)$ and obese $\left(\geq 30 \mathrm{~kg} / \mathrm{m}^{2}\right)$ following the $\mathrm{WHO}$ which addresses obesity during pregnancy as well as the general population [28].

\section{Statistics}

SPSS for Windows (version 16.0) was used for data analyses. A total sample size of 338 participants was calculated using the previous incidence of obesity (19.4\%) among pregnant women in Sudan [3]. A formula was used to calculate the difference in the mean of the proposed variable (hemoglobin level as 11.0 and $10.6 \mathrm{~g} / \mathrm{dl}$ in the obese and normal weight women, respectively) that would provide $80 \%$ power to detect a $5 \%$ difference at $\alpha=0.05$, with an assumption that complete data might not be available for $10 \%$ of participants. One-way analysis of variance (with post hoc 
Table 2. Comparison of sociodemographic, medical and obstetric characteristics between BMI groups among early-pregnancy Sudanese women.

\begin{tabular}{|c|c|c|c|c|c|}
\hline Variables & $\begin{array}{l}\text { Underweight } \\
\text { n (15) }\end{array}$ & Normal n (95) & $\begin{array}{l}\text { Overweight } \\
\text { n (127) }\end{array}$ & Obese n (101) & p-value \\
\hline \multicolumn{6}{|l|}{ The mean (SD) } \\
\hline Gravidity & $2.1(1.9)$ & $1.7(1.1)$ & $2.4(1.7)$ & $2.7(1.7)$ & $<0.001$ \\
\hline Parity & $0.5(0.9)$ & $0.5(0.8)$ & $1.1(1.4)$ & $1.3(1.3)$ & $<0.001$ \\
\hline Interpregnancy interval & $48.2(27.0)$ & $32.3(21.4)$ & $37.1(23.1)$ & $42.2(26.7)$ & 0.225 \\
\hline BMI, 18.5 kg/m² & $17.2(0.8)$ & $22.5(1.7)$ & $27.3(1.4)$ & $34.5(4.1)$ & $<0.001$ \\
\hline Hemoglobin (gm/dl) & $10.1(1.4)$ & $10.6(1.0)$ & $11.0(1.0)$ & $11.0(1.1)$ & 0.003 \\
\hline White blood cell (cells $\times 10^{9} / \mathrm{l}$ ): & $6100(1430)$ & $7446(1988)$ & $7937(2104)$ & $8013(2396)$ & 0.004 \\
\hline - Neutrophils & 3788 (1197) & $4902(1590)$ & $5164(1828)$ & $5253(2015)$ & 0.022 \\
\hline Red cells distribution width (\%) & $13.8(1.6)$ & $13.8(1.6)$ & $13.7(1.5)$ & $13.8(1.6)$ & 0.934 \\
\hline \multicolumn{6}{|l|}{ Number (\%) of } \\
\hline Rural residence & $4(26.7)$ & $19(20)$ & $13(10.2)$ & $12(11.9)$ & 0.085 \\
\hline Education level $\leq$ secondary level & $1(6.7)$ & $13(13.7)$ & $16(12.6)$ & $16(15.8)$ & 0.764 \\
\hline Housewives & $12(80)$ & $71(74.7)$ & $95(74.8)$ & $74(73.3)$ & 0.955 \\
\hline Anemia & $10(66.7)$ & $56(58.9)$ & $56(44.1)$ & $46(45.5)$ & 0.064 \\
\hline
\end{tabular}

Bonferroni tests) and $\chi^{2}$ tests were used to compare the normally distributed continuous variables and proportions between BMI groups. The variables of the one-way analysis of variance and $\chi^{2}$ test were entered (if $\mathrm{p}<0.2$ ) in a multinomial logistic regression (stepwise with forward entry) where BMI group was the dependent variable and sociodemographic parameters (age, parity, education, job, residence), hemoglobin levels and white blood cells (WBCs) count were the independent variables. Odds ratio (OR) and $95 \% \mathrm{CI}$ were calculated, using women with normal weight as the control group. $\mathrm{p}<0.05$ was considered statistically significant at two-sided test.

\section{Ethics}

The study received ethical clearance from the Research Board at the Department of Obstetrics and Gynecology, Faculty of Medicine, University of Khartoum, Sudan.

\section{Results}

General characteristics of the 338 enrolled women are shown in Table 1. Over half $(176,52.1 \%)$ of the women were primiparae. The mean (standard deviation) of the age, parity and gestational age was 27.8 (5.5) years, 0.9 (1.2) and 10.5 (3.1) weeks, respectively. Approximately half $(168,49.7 \%)$ of these women were anemic (hemoglobin $<11 \mathrm{gm} / \mathrm{dl}$ ).
Of the 338 enrolled women, 15 (4.4\%), 95 (28.1\%), 127 (37.6\%) and 101 (29.9\%) were underweight, normal BMI, overweight and obese, respectively (Table 2).

While there was no significant difference in residence, education and occupation, age and parity, and hemoglobin levels were significantly higher in obese than normal groups and they were higher with increasing BMI (Table 2). In comparison with the normal weight group, the mean (standard deviation) of the hemoglobin level was significantly higher in overweight (10.6 [1.0] vs 11.0 [1.0]g, $\mathrm{p}=0.007)$ and obese women $(10.6[1.0]$ vs 11.0 [1.1]g, $\mathrm{p}=0.040)$, however there was no significant difference in hemoglobin level between the overweight and obese groups (Figure 1).

Interestingly, although reaching borderline significance $(p=0.064)$, there was no significant difference in the prevalence of anemia between groups.

While WBC count was significantly lower in underweight than in normal weight women, there was no significant difference in WBC count between normal weight, overweight and obese women (Figure 2).

In the multinomial analyses, while there was no significant difference in age, residence and educational level between the different BMI groups, parity was higher with increasing BMI (OR [95\% CI]: 1.6 [1.1-2.2]; $\mathrm{p}=0.003$ and $1.7[1.2-2.4] ; \mathrm{p}=0.001$ for the overweight and obese women, respectively). In 


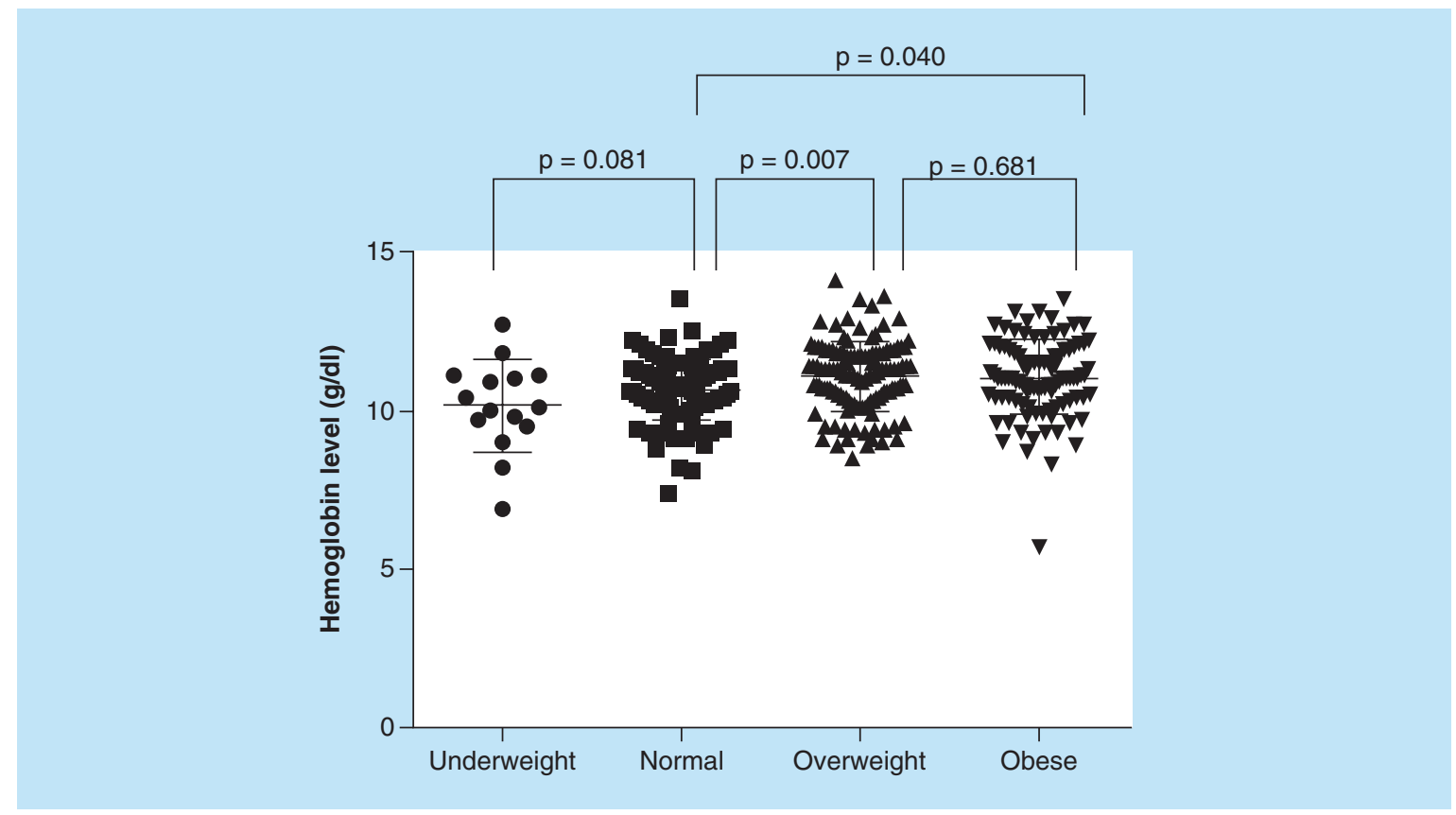

Figure 1. Relationship between hemoglobin concentration and BMI categories.

comparison to normal weight, overweight and obesity were associated with higher hemoglobin level (OR: $1.4[1.1-1.8]$ and $1.3[1.06-1.8]$, respectively). The OR for WBC count in the underweight and obese women compared with normal weight women were $0.6(0.4-0.9) ; \mathrm{p}=0.012$ and $1.1(0.9-1.3) ; \mathrm{p}=0.054$, respectively. Neutrophils were only significantly different in the underweight compared with normal weight group (OR: 0.5 [0.3-0.8]; $\mathrm{p}=0.013$ ) (Table 3).

\section{Discussion}

A recent meta-analysis showed that the prevalence of maternal obesity across Africa ranged from 6.5 to
$50.7 \%$ [4]. The current study found a high (29.9\%) prevalence of obesity among pregnant women (especially women with high parity) in their early pregnancy independent of their residence, education and occupation. Recently a much lower prevalence (19.4\%) of obesity was reported among pregnant women in Khartoum, Sudan [3]. Even though these two studies were conducted in the same setting (Khartoum), socioeconomic and methodological factors could explain this discrepancy. The current study was conducted in a semiprivate hospital, while that of Rayis et al. was conducted in a general hospital, possibly reflecting a hidden bias based on socioeconomic factors. Notably, it is diffi-

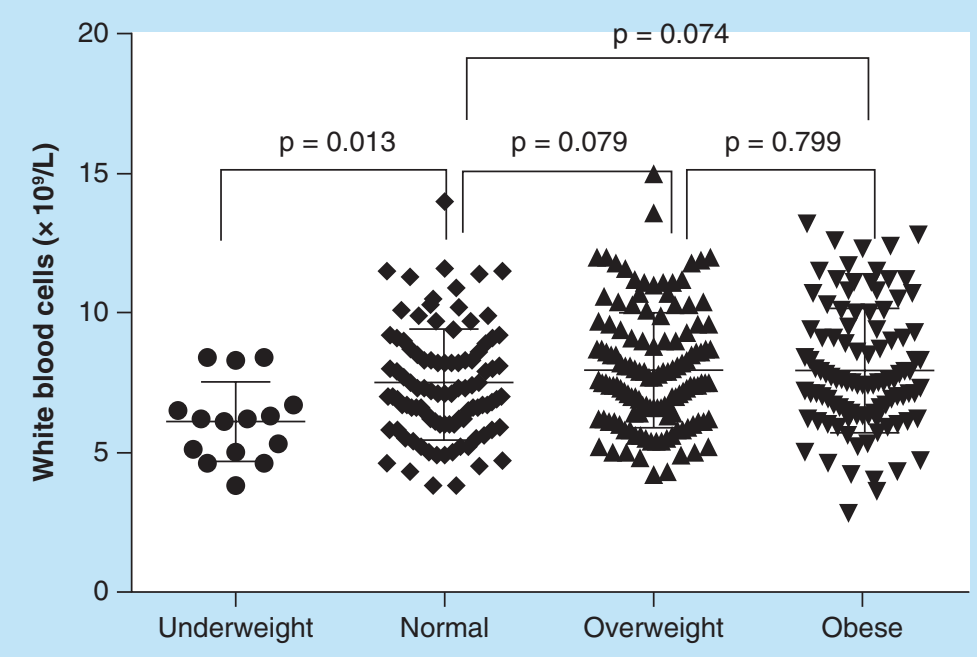

Figure 2. Relationship between white blood cell count and BMI categories. 
Table 3. Multinomial analyses of the factors associated with underweight, overweight and obesity.

\begin{tabular}{|llll|}
\hline Variables & Underweight $(\mathbf{n}=15)$ & Overweight $(\mathbf{n}=127)$ & Obese $(\mathbf{n}=101)$ \\
\hline Age (years) & $1.05(0.9-1.2) ; 0.423$ & $1.0(0.9-1.0) ; 0.555$ & $1.0(0.9-1.1) ; 0.409$ \\
\hline Parity $^{\dagger}$ & $0.7(0.3-1.5) ; 0.435$ & $1.6(1.1-2.2) ; 0.003$ & $1.7(1.2-2.4) ; 0.001$ \\
\hline Hemoglobin (gm/dl) & $0.6(0.4-1.0) ; 0.091$ & $1.4(1.1-1.8) ; 0.005$ & $1.3(1.06-1.8) ; 0.016$ \\
\hline White blood cells & $0.6(0.4-0.9) ; 0.012$ & $1.1(0.9-1.2) ; 0.075$ & $1.1(0.9-1.3) ; 0.054$ \\
\hline Neutrophils & $0.5(0.3-0.8) ; 0.013$ & $1.1(0.9-1.2) ; 0.210$ & $1.1(0.9-1.3) ; 0.125$ \\
\hline $\begin{array}{l}\text { Data expressed as odds ratio (95\% Cl); p-value. } \\
\text { 'Adjusted for age; white blood cells and neutrophils were entered one by one in each model. }\end{array}$ \\
\hline
\end{tabular}

cult (if not impossible) to investigate socioeconomic factors in Sudanese women, as the flow of income between relatives and neighbors common in this culture can confound accurate income assessment. The other difference between the studies was that Rayis et al. studied women in their later gestational age while the current study assessed women in their early gestational age.

In the current study, age was associated with obesity in the univariate analyses alone, with no significant association between age and obesity in the multinomial analyses. Therefore, age was considered as a confounder. In the previous report in the same setting, maternal obesity was positively associated with age (OR: 1.1; 95\% CI: 1.08-1.2) [2]. Moreover, it has also been reported that obesity increased with increasing maternal age among Nigerian women [29] as well as among African women as general according to a recent meta-analysis [4].

The current study showed that women with high parity were at higher risk of obesity, which supports previous reports $[4,29]$. A possible explanation for this could be that most women do not return to their prepregnancy weight after giving birth, which might result in a higher weight in subsequent pregnancies. Alternatively, there may have been a cumulative weight gain throughout the previous pregnancies.

The prevalence of anemia in this report was higher than that previously observed in the same setting. Interestingly, while there were no significant group differences in the prevalence of anemia, hemoglobin level was significantly higher in obese women.

Our finding of higher hemoglobin levels among overweight and obese women compared with normal weight women accords with previous reports. Another study examining stillbirth found that higher BMI was associated with higher hemoglobin levels at the first antenatal visit [30]. Likewise, Kordas et al. [17] reported that overweight and obesity were associated with a lower likelihood of anemia among nonpregnant Colombian women in the reproductive age, and that overweight and obese women had higher estimates of hemoglobin.

On the contrary, in a small ( 23 women in each arm) study Crabb and Chamberlin reported significantly lower hemoglobin levels in obese patients when compared with their normal weight peers [31]. However, this study may differ as it was conducted in the second trimester while we investigated the first, and it was of small sample size.

The current study's results are also in contrast to the findings of a recent meta-analysis of 26 studies of nonpregnant women, including 13,393 overweight/obese individuals and 26,621 nonoverweight participants. The overweight/obese participants had lower serum iron concentrations than the nonoverweight and had a significantly increased risk of iron deficiency (OR: 1.31; 95\% CI: 1.01-1.68) [32]. However, we have to acknowledge that serum ferritin is a better measure of iron status than hemoglobin level, so with just using the data on hemoglobin, the comparison will not precisely reflect the differences. Pregnant women may be different from nonpregnant women in this respect; accordingly, caution should be used in comparing results from these studies.

One of the limitations of the current study is that serum ferritin and C-reactive protein were not investigated. However, as according to WHO reports, the dominant type of anemia among pregnant women is iron deficiency [33], this limitation should be relatively minor. As an alternative to measuring serum ferritin, we relied on red cell distribution width, one of the components of the hemogram, as it is considered to be an inflammatory marker and a substitute for serum ferritin in diagnosing iron deficiency anemia [34]. Moreover, our previous studies showed no association between anemia and C-reactive protein [35]. Hemoglobinopathies and other factors that could have effects on hemoglobin level, such as smoking, were not investigated and thus this has to be considered a limitation of the current study. Smoking was not asked for because we feared loss of cooperation, as it is not socially acceptable among Sudanese women.

However, the current study's results showed that WBC count was significantly associated with overweight and obesity. This is in alignment with reports discussing the inflammatory nature of obesity [36,37]. 
Plausible explanations for the anemia among obese individuals were: dietary iron deficiency, increased demand for iron due to increased blood volume and physical inactivity and low-grade inflammation [6-8]. Furthermore, hepcidin (an iron-regulatory protein) and obesity-associated low-grade inflammation might play a pivotal role in the regulation of iron homeostasis [9,13-15]. Notably, anemia was present in approximately $50 \%$ of the current study's population. This high prevalence is in concordance with our previous finding of low usage of iron and folate supplementation among pregnant Sudanese women during their first trimester [38]. It is to be mentioned that BMI was taken in the early where prepregnancy BMI and weight gain during pregnancy might be difficult to get in our setting. Finally, the high hemoglobin level among obese women may be due to the nutritional status of obese group, for example intake of high iron foods.

\section{Conclusion}

In the current study, obese women had higher WBC count and higher hemoglobin levels, and were more likely to be of older age and multiparae compared with nonobese women. This could reflect the inflammatory nature of obesity and warrants further study to better understand these findings.

\section{Future perspective}

Given the increasing rate of obesity worldwide, where pregnant women are a vulnerable group, more effort is needed to explore the pathophysiology of obesity during pregnancy. The association between obesity and anemia (especially iron deficiency) might reflect the poor nutrition of obese women. Many biomarkers, for example ferritin and hepcidin, need to be investigated in depth. Furthermore, chemokines could have their influence in the pathophysiology of obesity. A longi-

Executive summary

- Obesity among pregnant women is a globally recognized, contentious public health problem, and can lead to adverse maternal and fetal outcomes.

- While there has been a great deal of research into the association between anemia/hemoglobin levels and obesity among nonpregnant women, there are no published data on hemoglobin levels and obesity among pregnant women.

- The objective of this study was to investigate the prevalence of obesity and the association between obesity, hemoglobin levels and white blood cells (WBCs) count among a population of Sudanese women in their early pregnancy.

- A cross-sectional study was conducted at Saad Abualila Hospital (Khartoum, Sudan) during the period of January-April 2014.

- Sociodemographic, medical and obstetric data were collected using questionnaires. Weight and height were determined, and BMI was calculated.

- The complete maternal hemogram was measured for all participants.

- One-way analysis of variance and $\chi^{2}$ tests were used to compare the normally distributed continuous variables and proportions between BMI groups.

- A multinomial logistic regression was conducted where the BMI group was the dependent variable and sociodemographic parameters, hemoglobin levels and WBC count were the independent variables.

- $p<0.05$ was considered statistically significant at two-sided test.

- The mean (standard deviation) of the age, parity and gestational age was 27.8 (5.5) years, 0.9 (1.2) and 10.5 (3.1) weeks, respectively.

- There were 15 (4.4\%), 95 (28.1\%), $127(37.6)$ and $101(29.9 \%)$ women who were underweight $\left(<18.5 \mathrm{~kg} / \mathrm{m}^{2}\right)$, normal weight $\left(18.5-24.9 \mathrm{~kg} / \mathrm{m}^{2}\right)$, overweight $\left(25-29.9 \mathrm{~kg} / \mathrm{m}^{2}\right)$ and obese $\left(\geq 30 \mathrm{~kg} / \mathrm{m}^{2}\right)$, respectively.

- While there was no significant difference in education level, residence and occupation, age and parity, hemoglobin levels and WBC count were significantly higher in obese than nonobese groups and were higher with increasing BMI.

- In the multinomial analyses, parity was higher with increasing BMI for the overweight and obese women. Hemoglobin levels were higher with increasing BMI, with odds ratios $(95 \% \mathrm{Cl})$ of $0.6(0.4-1.0), 1.4(1.1-1.8)$ and 1.3 (1.06-1.8), for underweight, overweight and obese women, respectively.

- The odds ratios for WBC count in the underweight and obese women compared with normal weight women were $0.6(0.4-0.9)$ and $1.1(0.9-1.3)$, respectively.

- Previous study reported a significantly lower second trimester hemoglobin levels in obese patients when compared with their normal weight peers.

- On other hand another study examining stillbirth found that higher BMI was associated with higher hemoglobin levels at the first antenatal visit.

- A longitudinal study to investigate iron parameters and gestational diabetes and other adverse effects of hemoglobin level on the maternal and perinatal outcome is needed. 
tudinal study investigating iron parameters and gestational diabetes and the effects of hemoglobin level on the maternal and perinatal outcome is needed.

\section{Acknowledgements}

The authors thank the participants of the study.

\section{Authors' contributions}

A Elmugabil and I Aadam designed the study. DA Rayis and RE Abdelmageed conducted the clinical work, I Adam and GI Gasim performed the statistical analyses. All the authors shared drafting the paper and approved this work.

\section{Financial \& competing interests disclosure}

The authors have no relevant affiliations or financial involvement with any organization or entity with a financial interest in or financial conflict with the subject matter or materials discussed in the manuscript. This includes employ-

\section{References}

Papers of special note have been highlighted as:

- of interest; $\bullet \bullet$ of considerable interest

1 Mitchell N, Catenacci V, Wyatt HR, Hill JO. Obesity: overview of an epidemic. Psychiatr. Clin. North. Am. 34, 717-732 (2011).

2 Fisher SC, Kim SY, Sharma AJ, Rochat R, Morrow B. Is obesity still increasing among pregnant women? Prepregnancy obesity trends in 20 states, 2003-2009. Prev. Med. 56, 372-378 (2013).

3 Rayis DA, Abbaker AO, Salih Y, Diab TE, Adam I. Epidemiology of underweight and overweight-obesity among term pregnant Sudanese women. BMC Res. Notes 6(3), 327 (2010).

- The first study that pointed to the obesity during pregnancy in Sudan.

4 Onubi OJ, Marais D, Aucott L, Okonofua F, Poobalan AS. Maternal obesity in Africa: a systematic review and metaanalysis. J. Public. Health (Oxf.) 38(3), e218-e231 (2016).

- A recent metanalysis of obesity during pregnancy in Africa.

5 Wenzel BJ, Stults HB, Mayer J. Hypoferraemia in obese adolescents. Lancet 2, 327-328 (1962).

6 Rao GM, Morghom LO. Effect of obesity on erythrocyte count and hemoglobin levels in Libyan diabetic patients. Clin. Physiol. Biochem. 4, 277-280 (1986).

7 Pinhas-Hamiel O, Newfield RS, Koren I, Agmon A, Lilos P, Phillip M. Greater prevalence of iron deficiency in overweight and obese children and adolescents. Int. J Obes. Relat. Metab. Disord. 27, 416-418 (2003).

- Reported association between iron deficiency and obesity.

8 Winther SA, Finer N, Sharma AM, Torp-Pedersen C, Andersson C. Association of anemia with the risk of cardiovascular adverse events in overweight/obese patients. Int. J. Obes. (Lond.) 38, 432-437 (2014).

9 Cepeda-Lopez AC, Osendarp SJ, Melse-Boonstra A et al. Sharply higher rates of iron deficiency in obese Mexican ment, consultancies, honoraria, stock ownership or options, expert testimony, grants or patents received or pending, or royalties.

No writing assistance was utilized in the production of this manuscript.

\section{Ethical conduct of research}

The authors state that they have obtained appropriate institutional review board approval or have followed the principles outlined in the Declaration of Helsinki for all human or animal experimental investigations. In addition, for investigations involving human subjects, informed consent has been obtained from the participants involved.

\section{Open access}

This work is licensed under the Creative Commons Attribution 4.0 License. To view a copy of this license, visit http://creativecommons.org/licenses/by/4.0/

women and children are predicted by obesity-related inflammation rather than by differences in dietary iron intake. Am. J. Clin. Nutr. 93, 975-983 (2011).

10 De Benoist B, McLean E, Egli I, Cogswell M. Worldwide Prevalence of Anaemia 1993-2005: WHO Global Database on Anaemia, WHO, Geneva, Switzerland, 2008. http://apps.who.int/

11 Ramsay Margaret. Normal hematological changes during pregnancy and the puerperium. In: The Obstetric Hematology Manual. Pavord S, Hunt B (Eds). Cambridge University Press, Cambridge, UK, 1-11 (2010).

12 Groenveld HF, Januzzi JL, Damman K et al. Anemia and mortality in heart failure patients a systematic review and meta-analysis. J. Am. Coll. Cardiol. 52, 818-827 (2008).

13 Vuppalanchi R, Troutt JS, Konrad RJ et al. Serum hepcidin levels are associated with obesity but not liver disease. Obesity (Silver Spring), 22, 836-841 (2014).

- Investigated the association between hepcidin and obesity.

14 Cheng HL, Bryant CE, Rooney KB et al. Iron, hepcidin and inflammatory status of young healthy overweight and obese women in Australia. PLoS ONE 4(8), e68675 (2013).

15 Villarroel HP, Arredondo OM, Olivares GM. Hepcidin as a central mediator of anemia of chronic diseases associated with obesity. Rev. Med. Chil. 141, 887-894 (2013).

16 Chang JS, Li YL, Lu CH, Owaga E, Chen WY, Chiou HY. Interleukin-10 as a potential regulator of hepcidin homeostasis in overweight and obese children: a crosssectional study in Taiwan. Nutrition 30, 1165-1170 (2014).

17 Kordas K, Fonseca Centeno ZY, Pachón H, Jimenez Soto AZ. Being overweight or obese is associated with lower prevalence of anemia among Colombian women of reproductive age. J. Nutr. 143, 175-181 (2013).

18 Gartner A, El Ati J, Traissac P et al. A double burden of overall or central adiposity and anemia or iron deficiency is prevalent but with little socioeconomic patterning among Moroccan and Tunisian urban women. J. Nutr. 144, 87-97 (2014). 
- Documented the association between anemia and obesity among women.

19 Ghadiri-Anari A, Nazemian N, Vahedian-Ardakani HA. Association of body mass index with hemoglobin concentration and iron parameters in Iranian population. ISRN Hematol. 2014, 525312 (2014).

20 Manios Y, Moschonis G, Chrousos GP et al. The double burden of obesity and iron deficiency on children and adolescents in Greece: the Healthy Growth Study. J. Hum. Nutr. Diet. 26, 470-478 (2013).

21 Begum KS, Sachchithanantham K, De Somsubhra S. Maternal obesity and pregnancy outcome. Clin. Exp. Obstet. Gynecol. 38, 14-20 (2011).

22 Papachatzi E, Dimitriou G, Dimitropoulos K, Vantarakis A. Pre-pregnancy obesity: maternal, neonatal and childhood outcomes. J. Neonatal. Perinatal. Med. 6, 203-216 (2013).

23 Rayis DA, Abbaker AO, Salih Y, Adam I. Obesity and pregnancy outcome in Khartoum, Sudan. Int. J. Gynaecol. Obstet. 113, 160-161 (2011).

24 Morgan KL, Rahman MA, Hill RA, Khanom A, Lyons RA, Brophy ST. Obesity in pregnancy: infant health service utilisation and costs on the NHS. BMJ Open 26(5), e008357 (2015).

25 Adam I, Ahmed S, Mahmoud MH, Yassin MI. Comparison of $\mathrm{HemoCu}{ }^{\circledR}$ hemoglobin-meter and automated hematology analyzer in measurement of hemoglobin levels in pregnant women at Khartoum hospital, Sudan. Diagn. Pathol. 7, 30 (2012).

26 Abdelrahman EG, Gasim GI, Musa IR, Elbashir LM, Adam I. Red blood cell distribution width and iron deficiency anemia among pregnant Sudanese women. Diagn. Pathol. 7 , 168 (2012).

27 Sysmex KX-21 N Operator's Manual: Sysmex Corporation. 2006.

www.blockscientificstore.com/

28 WHO. Maternal body mass index and gestational weight gain and their association with perinatal outcomes in Vietnam.

www.who.int/bulletin/volumes/89/2/10-077982/en/
29 Okoh M. Socio-demographic correlates of overweight and obesity among women of reproductive age in Nigeria. Afr. J. Reprod. Health 17, 66-76 (2013).

30 Stephansson O, Dickman PW, Johansson A, Cnattingius S. Maternal hemoglobin concentration during pregnancy and risk of stillbirth. JAMA 284(20), 2611-2617 (2000).

31 Crabb AM, Chamberlin R. Hemoglobin levels in normalweight and obese patients during pregnancy. J Reprod. Med. 57(3-4), 105-8 (2012).

- Investigated the same objective.

32 Zhao L, Zhang X, Shen Y, Fang X, Wang Y, Wang F. Obesity and iron deficiency: a quantitative meta-analysis. Obes. Rev. 16, 1081-1093 (2015).

33 Iron Deficiency Anaemia: Assessment, Prevention, and Control. A guide for programme managers. www.who.int/nutrition/

34 Sultana GS, Haque SA, Sultana T, Ahmed AN. Value of red cell distribution width (RDW) and RBC indices in the detection of iron deficiency anemia. Mymensingh. Med. J. 22, 370-376 (2013).

35 Mohamed AA, Ali AA, Ali NI, Abusalama EH, Elbashir MI, Adam I. Zinc, parity, infection, and severe anemia among pregnant women in Kassla, eastern Sudan. Biol. Trace Elem. Res. 140, 284-290 (2011).

36 Karakelides H, Irving BA, Short KR, O'Brien P, Nair KS. Age, obesity, and sex effects on insulin sensitivity and skeletal muscle mitochondrial function. Diabetes 59, 89-97 (2010).

37 Farhangi MA, Keshavarz SA, Eshraghian M, Ostadrahimi A, Saboor-Yaraghi AA. White blood cell count in women: relation to inflammatory biomarkers, haematological profiles, visceral adiposity, and other cardiovascular risk factors. J. Health Popul. Nutr. 31, 58-64 (2013).

- Investigated the white blood cell and obesity.

38 Abdullahi H, Gasim GI, Saeed A, Imam AM, Adam I. Antenatal iron and folic acid supplementation use by pregnant women in Khartoum, Sudan. BMC Res. Notes 7 , 498 (2014). 